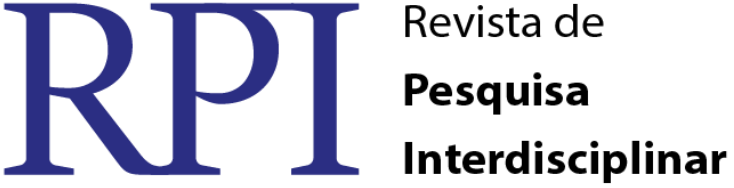

\section{DESAFIOS E PERSPECTIVAS DA GESTÃO ESCOLAR SOB A ÓTICA DA ABORDAGEM COMPORTAMENTAL}

\author{
Francisca Lindervânia Diniz Lopes - UAE/CFP/UFCG ${ }^{1}$ \\ Josefa Laureana de Sousa Andrade - UAE/CFP/UFCG ${ }^{2}$ \\ Wiama de Jesus Freitas Lopes ${ }^{3}$
}

\begin{abstract}
RESUMO
Discutimos neste trabalho o estudo da administração escolar sob a ótica da Teoria Comportamental, dando ênfase à compreensão das relações humanas. Tendo a motivação como principal meio para o desenvolvimento do trabalho dentro do ambiente escolar. Esta teoria surgiu em 1947, tendo como fundamento o comportamento individual e coletivo das pessoas. Nesta perspectiva autores como Herbert Simon e Maslow, principais precursores, direcionaram suas atenções a esta ciência, acreditavam que seria capaz de compreender não apenas o lado social, mas também o racional do trabalhador. Com o objetivo de conhecer as reações interpessoais ocorridas no ambiente escolar, especificamente em uma Escola Pública Estadual, localizada no centro da cidade de Cajazeiras-PB. Realizamos um estudo de campo buscando entender as complexidades das relações entre gestor e demais sujeitos da ação. Foi uma atividade realizada na disciplina de Teorias da Gestão no curso de Licenciatura em Pedagogia. A elaboração se deu através de estudos bibliográficos e estudo de campo, ocorridos no ambiente da escola. O estudo de campo ocorreu com uma conversa informa com a então gestora da unidade escolar acima descrita, abordando temas como a relação gestão e funcionários, valorização dos mesmos, formação continuada de professores e a relação da gestão com a comunidade escolar. Na medida do possível, a gestora esclareceu nossas indagações, visto que em alguns momentos, não demostrou segurança e conhecimento sobre a teoria abordada, na qual fundamentávamos nossa conversa. Após a coleta de dados realizamos a analise e apresentação de resultados ao professor da disciplina e demais colegas de turma.
\end{abstract}

Palavras-chave: Teoria comportamental, gestão escolar, relações interpessoais.

\section{CHALLENGES AND MANAGEMENT OUTLOOK SCHOOL FROM THE PERSPECTIVE OF BEHAVIORAL APPROACH}

\begin{abstract}
\footnotetext{
${ }^{1}$ Graduanda do Curso de Pedagogia - UAE/CFP/UFCG - Email: lindervaniadiniz@ outlook.com

${ }^{2}$ Graduanda do Curso de Pedagogia - UAE/CFP/UFCG Email: laurianasousa1 @ hotmail.com

${ }^{3}$ Docente do curso de Pedagogia - UAE/CFP/UFCG Emai: uiama@uol.com.br
}

We discuss in this paper the study of school administration from the perspective of behavioral theory, emphasizing the understanding of human relationships. Having motivation as the primary means for the development of the work within the school environment. This theory emerged in 1947, and is based upon the individual and collective behavior of people. In this perspective authors like Herbert Simon and Maslow, key precursors, they directed their attention to this science, believed it would be able to understand not just the social side, but also the rational worker. In order to meet the interpersonal reactions that occur in the school environment, specifically in a State Public School, 
located in the center of Cajazeiras-PB. We conducted a field study seeking to understand the complexities of the relationship between manager and other subjects of the action. It was an activity performed in the management theories of discipline in the Bachelor's Degree in Education. The preparation was made through bibliographic research and field study took place in the school environment. The field study was carried out with a conversation with the then informs the management of the school unit described above, covering topics such as relationship management and employees, value thereof, continued teacher training and relationship management with the school community. As far as possible, the management clarified our inquiries, as at times, did not show safety and knowledge of the theory discussed in which fundamentávamos our conversation. After collecting data to perform analysis and reporting results to the subject teacher and other classmates.

Keywords: behavioral theory, school management, interpersonal relationships

\section{INTRODUÇÃO}

O presente artigo tem por objetivo o estudo da administração escolar sob a ótica da Teoria Comportamental, dando ênfase à compreensão das relações humanas, tendo a motivação, como principal meio para o desenvolvimento do trabalho no ambiente escolar. Autores como Herbert Simon e Maslow, principais precursores, direcionaram suas atenções a uma ciência, acreditavam, seria capaz de compreender não apenas o lado social, mas também o racional do trabalhador.

Partindo do pressuposto teóricos, Krumm (2011), Sousa (2006), o trabalhador deve ser observado como um ser que necessita ser compreendido na sua totalidade social e racional, este trabalho faz uma análise referente às observações em torno da função da gestão de uma escola pública.

Em busca de respostas as diversas inquietações que surgiram durante a pesquisa bibliográfica e ao conhecemos a realidade da gestão escolar, através de um estudo de campo realizado em uma escola publica estadual, localizado no centro da cidade de Cajazeiras - PB, observando o ambiente e dialogicamente interagindo com seus integrantes na intenção de encontrar conhecimentos e, ou traços da teoria comportamental. Delinearemos as atividades e desafios encontrados no cotidiano escolar, que veio favorecer uma visão e apreciação da realidade educacional em que se encontra a instituição, bem como nossas reflexões desenvolvidas durante os estudos sobre a teoria comportamental.

A partir da observação realizada no estudo de campo foi possível analisar se a escola observada tem traços predominantes da Teoria Comportamental, e se existem, quais os elementos que caracterizam sua prática enquanto desenvolvimento e integração das relações. RPI Revista de Pesquisa Interdisciplinar, Cajazeiras, v. 1, Ed. Especial, 221 - 228, set/dez. de 2016. 
Sob a ótica comportamentalista, é possível uma gestão preocupar-se não apenas com os resultados a serem obtidos, ou com as pessoas, e sim com a relação entre estes, todos os resultados obtidos dependeram da relação intrínseca que há entre o sujeito e suas ações, resultando, ou não, em efetivo sucesso.

A Gestão escolar tem a função de dirigir e orientar todas as atividades desenvolvidas dentro do ambiente escolar e intrinsecamente relacionadas à comunidade. Podemos entender que, uma gestão perpassa os muros da instituição, com características bastante peculiares indo além dos assuntos técnicos e burocráticos. Preocupada com a qualidade, seus resultados não podem ser facilmente quantificados, pois lida com o saber. Seu objeto é o educando, que ao mesmo tempo é sujeito da ação, pois além de ser personagem principal da ação está diretamente relacionada a ela.

A escola não escolhe cliente ou matéria prima, devido ao seu caráter social, deve atender a todos sem distinção, visando sempre o bem comum e o crescimento pessoal e social dos indivíduos. Para que consiga entender e melhor identificar o crescimento, ou não, dos resultados, se faz necessário um preparo e dedicação do gestor e sua equipe.

A administração é uma prática que surge a partir de uma lógica, seja ela de caráter particular ou pública com objetivos definidos a sua existência, sendo assim, o seu desenvolvimento contribui para intermediar práticas sociáveis individuais ou coletivas. A finalidade principal é organizar, controlar as diversas funções, resultando em trabalhos eficientes e satisfação coletiva.

De acordo com estudos, a abordagem comportamental surgiu no final da década de quarenta como protestos as formas de administração, o ser humano era entendido como uma máquina produtora de mão de obra, só os superiores podiam tomar decisões, cabendo aos trabalhadores exercer as tarefas por aqueles comandadas. "[...] o enfoque dentro da abordagem das ciências do comportamento é o abandono das posições normativas e prescritivas das teorias anteriores e a adoção de posições explicativas e descritivas". (FGV online, s.a, p. 01).

Seus maiores expoentes foram o norte americano Herbert Simon que procurou entender o comportamento humano dentro das organizações através de uma técnica que ele chamava de processo decisorial, em que concebia o ser humano como capaz de fazer parte do processo de decisões nas organizações, como seres participantes, assim sendo estariam 
diretamente ligados aos resultados alcançados. Outro grande nome, Abraham Maslow responsável pela elaboração de uma pirâmide das necessidades, que será apresentada abaixo.

Tendo como objeto de "estudo o comportamento individual e coletivo das pessoas, mostrando ser possível a busca por uma maior aproximação entre a pessoa e as organizações". Sousa (2006, p. 54). A relação com a gestão escolar tem, na pessoa, seu objeto de trabalho, em uma relação bastante complexa, visto que, toda dinâmica está voltada para o ser humano.

Com isto, foram surgindo conceitos e críticas sobre a forma como era abordada a organização do trabalho, buscando uma melhor valorização do trabalhador garantindo assim, segundo a abordagem, um maior desempenho das atividades por ele desenvolvidas, favorecendo a sua autorealização.

Sousa (2006, p.55), afirma que "para os defensores da Teoria comportamental o trabalho das pessoas deve mostrar-se, ao mesmo tempo, eficaz e eficiente, ao tempo em que alcança não apenas os objetivos da instituição, como também, os objetivos pessoais". O que implica dizer que o gestor de uma instituição deve preocupar-se em fazer bem seu trabalho e com responsabilidade, garantido qualidade.

Para tanto é preciso que haja previsibilidade de ações, controle na execução do que foi planeado e liderança para saber lidar com os conflitos, conduzindo de modo competente a resolução. Podemos entender que a gestão não sofre influência de uma abordagem apenas, mas está ligada a orientações advindas de outras concepções, contudo não deve fugir à atenção dos fundamentos da Teoria Comportamental.

Desta forma, a gestão estará contribuindo de forma diversificada e democrática com o desenvolvimento do trabalho coletivo, intencionando garantir uma administração equilibrada capaz de manter um relacionamento entre o meio interno e externo. A gestão pública e, ou privada vai além de necessitar manter uma preocupação voltada à dinâmica de interação no meio em que está inserida, será necessário fundamentar-se em outras Teorias, como a Burocrática, que contribuirá para a organização lógica do trabalho, com normas e regulamentos, garantindo a racionalidade na tomada de decisões, rotinas e procedimentos, entres outros, que vai assegurar o bom funcionamento da instituição.

Uma gestão não pode pautar seu trabalho apenas na Abordagem Comportamental, pois a administração requer uma organização burocrática, exemplo desta ligação entre as abordagens, na administração, está no respeito às regras, na divisão do trabalho e na obtenção do emprego baseando-se no mérito, que são características da Teoria Burocrática. Já das RPI Revista de Pesquisa Interdisciplinar, Cajazeiras, v. 1, Ed. Especial, 221 - 228, set/dez. de 2016. 
Relações Humanas trouxe a preocupação com as pessoas individualmente, seus anseios e a relação com a produtividade. Mesmo que críticas fortíssimas tenham sido direcionadas a Teoria última citada, visto que segundo sua organização todas as pessoas almejam crescimento profissional e novas responsabilidades, esquecendo-se das individualidades e tratando como sujeitos padronizados.

Na perspectiva da teoria comportamental, administração e gestão vão muito além de uma ação técnica e burocrática, um direcionamento voltado à participação e preocupação com as relações interpessoais, contribuindo de forma diversificada e democrática com o desenvolvimento do trabalho coletivo. Esta teoria vai tratar que, toda a dinâmica no ambiente de trabalho interfere diretamente nos resultados a serem alcançados.

As relações interpessoais, que consiste na interação entre os grupos de trabalho, como os funcionários são tratados em suas particularidades, quais condições de autonomia são oferecidas, as pessoas são ouvidas e suas reivindicações atendidas, na medida do possível. Todo isso fará uma grande diferença no desenvolvimento do trabalho.

Podemos destacar, ainda, as relações intrapessoais, que é a autocontenção, autoconhecimento e automotivação, isso influencia na capacidade de comunicar-se com o meio externo, revelando assim uma ligação intrínseca com a primeira. Para que os sujeitos possam lidar melhor com as interferências externas ele deve está sentindo bem interiormente, é um movimento íntimo, entre sujeitos/sujeitos/meio, desdobrando-se em rendimento, ou não, de suas capacidades intelectuais e sociais, no campo pessoal e profissional.

A Abordagem comportamentalista tem uma formação transversal, com sustentação em outras teorias como a teoria burocrática e das relações humanas.

Fundamentados no pensamento de Maslow, psicólogo norte americano, que trouxe a concepção de teoria da motivação, em que trata as necessidades humanas em níveis, seguindo uma importância hierárquica, afirmando que o ser humano necessita ter suas necessidades básicas garantidas e respeitadas, para que assim haja crescimento pessoal e profissional, isso seria possível seguindo as orientações explicitas através de uma pirâmide que representa as necessidades do individuo partindo de sua base como as necessidades fisiológicas, de segurança, sociais, de estima e no topo as mais elevadas que são as necessidades de autorealização.

Quando o ser humano ver-se em um ambiente acolhedor, em que não é apenas um executor de tarefas, mas pode participar de maneira efetiva de todo o processo de construção RPI Revista de Pesquisa Interdisciplinar, Cajazeiras, v. 1, Ed. Especial, 221 - 228, set/dez. de 2016. 
destas, desde a elaboração ate a execução, este mesmo profissional, direciona melhor suas capacidades para o desenvolvimento das ações.

Cabe a cada gestor dentro do plano de ação elaborar ações que estejam explicitamente com uma proposta de trabalho, condizente com a realidade dos funcionários e do próprio ambiente. As tarefas devem conter a praticidade e governabilidade de uma gestão do trabalho. Com a efetiva participação de todos, valorizando a prática coletiva, considerando o ser humano parte integrante dentro de um complexo sistema organizacional, em que se devem respeitar suas particularidades, como a do próprio sistema, seguindo tal orientação cada organização exercerá suas funções com grande êxito.

Como a ênfase do estudo é a gestão escolar, é possível observar o quanto a escola tem o seu papel eficaz numa sociedade. Pautada em uma administração que busca a democracia dentro do ambiente, desenvolvendo atividades que acrescentem e desenvolvam muito mais ações, além da participação e principalmente a socialização no processo educativo.

É possível dentro da concepção da administração comportamental, fazer um paralelo da atualidade e antiguidade quanto ao acesso nas escolas. $\mathrm{O}$ que percebemos são situações opostas, há tempos atrás, a educação era restrita a poucos, apenas as classes mais privilegiadas, enquanto que no decorrer dos tempos os direitos foram concedidos e assegurados para uma educação ao alcance de todos.

A importância dos funcionários das escolas conhecerem, como também desenvolverem boas práticas de gestão nas unidades escolares é necessária para que os mesmos compreendam o seu papel, com isso as atividades terão um crescimento de forma comprometida, responsável, relacionando o trabalho com todas as outras partes integradoras, se reconhecendo como elemento necessário das práticas educacionais.

Neste sentido o fortalecimento de uma participação objetiva a igualdade e autonomia entre os sujeitos. Reconhecer uma boa gestão vai muito além de, apenas liderar um grupo de funcionários, mas principalmente promover dentro do seu ambiente, situações que encaminhe e direcione as ações, além de favorecer o exercício da escola que é a educação como principal meio de ascensão e crescimento individual e coletivo.

Compreendemos que cabe a gestão promover e nortear diálogos e entendimentos entre todos os sujeitos da ação, momentos de socialização das atividades realizadas na escola, com os pais e a comunidade compartilhando resultados, buscando desta maneira, um bom rendimento das atividades. Característica da Abordagem comportamental, que vislumbra a RPI Revista de Pesquisa Interdisciplinar, Cajazeiras, v. 1, Ed. Especial, 221 - 228, set/dez. de 2016. 
participação de todos nas decisões em que se referem ao funcionamento da escola. Sem se eximir da responsabilidade de liderança que dela é exigida.

Todas estas ações irão contribuir para o crescimento da instituição, refletindo diretamente na aprendizagem dos alunos, com os professores desempenhando um trabalho pedagógico dinâmico, ficando evidente a satisfação e bem estar. Todo este processo de gestão organizacional, humanista e participativa direciona a qualidade de ensino adaptável às mudanças, envolvendo a estrutura física, funcional e cultural do ambiente, como também as relações interpessoais se propagam ao dialogo, aprendizagem, e a práxis.

Partindo da percepção de gestão como um processo que se responsabiliza por conduzir funções como planejar, organizar, dirigir e avaliar. Todo o seu desenvolvimento deve ser ordenado por objetivos que de maneira eficaz se faça cumprir, almejando no final a realização do trabalho e crescimento educacional. Portanto, este desenvolvimento deve acontecer de maneira planejada, onde exista a união de setores, trabalho coletivo entre administração, apoio pedagógico, professores e todas as pessoas que fazem parte da comunidade escolar, de forma democrática e participativa. Não se esquecendo de valorizar os sujeitos em suas particularidades, visto que são de pessoas que se constituem as organizações, aqui escolares.

\section{Considerações Finais}

A Teoria Comportamental é nos mostrou que os relacionamentos entre as funções hierárquicas, são possíveis e produtivos. Tanto o comportamento dos indivíduos, quantos dos grupos são considerados fatores importantes para a construção, funcionamento e desenvolvimento das organizações.

Foi possível concluir que a escola pesquisada está pautada em uma gestão que administra de forma democrática, com a participação efetiva de toda a comunidade escolar, levando sempre em consideração o seu contexto, visando a satisfação das necessidades primordiais no ambiente. Outro ponto que caracteriza uma gestão com base comportamentalista, é relacionado ao processo decisorial, em que todo indivíduo deve ser um tomador de decisões, assumindo atitudes e opiniões efetivamente participativas

Quanto as relações pessoais, também podemos observar que as estruturas das organizações não podem apresentar uma igualdade de dinâmica, cada sistema é ímpar em sua organização, cada indivíduo tem anseios diferentes, seja nas reações interpessoais, seja 
intrapessoal. Para que aconteça um bom funcionamento da instituição, é necessário antes de tudo um planejamento e a organização de todas as atividades, de modo que, envolvam desde a gestão administrativa até o planejamento de aulas, contando com o empenho e comprometimento de todos. Diante de toda esta necessidade organizacional é possível alcançar e traçar metas para que tenha o sucesso desejado.

Gestão é toda uma ação que se responsabiliza de conduzir funções como planejar, organizar, dirigir e avaliar. Todo o seu desenvolvimento deve ser pautado em objetivos que de maneira eficaz se faça cumprir, almejando no final a realização do trabalho e crescimento educacional. Portanto, deve acontecer de maneira planejada, onde exista a união de setores, trabalho coletivo entre administração, apoio pedagógico, professores e todas as pessoas que fazem parte da comunidade escolar, de forma democrática e participativa.

Nessa perspectiva, é preciso garantir o completo e eficiente funcionamento de todos os setores, sendo que, a escola disponha de um ambiente com condições favoráveis para a realização de tais atividades, promovendo meios e recursos satisfatório para que a unidade escolar tenha um bom funcionamento, articulando novas praticas educativa a serem desenvolvidas no ambiente de trabalho, garantindo assim, uma satisfação na realização das tarefas.

Com as transformações do mundo contemporâneo, a educação também permeia mudanças, dentro da gestão escolar também atenua essas modificações no processo organizacional, de maneira que não deixe de valorizar a autonomia e a participação.

Dentro do plano de ação da gestão cabe citar a importância de uma boa proposta de trabalho, que esteja de acordo com a realidade dos funcionários e do próprio ambiente. Referente à organização de tarefas quanto à praticidade das funções, na sua governabilidade, a gestão do trabalho é imprescindível a participação efetiva de todos, valorizando a sua prática e fortalecendo as relações entre o sistema de ensino e gestão.

Todo este processo de gestão organizacional aponta para o sucesso da qualidade de ensino que depende de mudanças adequadas ao âmbito escolar, envolvendo a sua estrutura física, funcional e cultural, como também as relações entre professores, alunos, e funcionários, tornando-se um ambiente aberto ao dialogo, aprendizagem, e a práxis.

\section{REFERÊNCIAS}

RPI Revista de Pesquisa Interdisciplinar, Cajazeiras, v. 1, Ed. Especial, 221 - 228, set/dez. de 2016. 
KRUMM, Diane J. Psicologia do trabalho: uma INTRODUÇÃO a psicologia industrial/organizacional: tradução Dalton Conde de Alencar; revisão técnica Marcos Aguiar de Souza-Rio de Janeiro: LTC; 2011.

SOUSA, Pedro Miguel Lopes de. Aprendizagem auto - regulada no contexto escolar: Uma abordagem Motivacional. Revista Psicologia. Coimbra, PT: 2006. 13 p. Disponível em: <http://www.psicologia.pt/ artigos/textos/A0295.pdf> Acessado em: 30 de novembro de 2014.

Abordagem Comportamental da Administração. Acesso em: https://www.google.com.br/search?q=SOUSA,+Pedro+Miguel+Lopes+de+Sousa.+Aprendiza gem+auto-regulada+no+contexto+escolar:+uma+abordagem+motivacional\&ie=utf$\underline{8 \text { \&oe }=\text { utf-8\&gws_rd }=\text { cr\&ei }=U \text { - }}$

JYVqXMI4HsmAGAuqeQDA\#q=fgv+online+abordagem+comportamental+da+administra\% C3\%A7\%C3\%A30.+[S.I.:+s.n] 